\title{
Uso de derivativos agropecuários como mecanismo de comercialização de soja, no município de Rio Verde, Goiás ${ }^{1}$
}

\author{
Leucivaldo Carneiro Morais ${ }^{2}$, Ivo Martins Cezar ${ }^{3}$, Celso Correia de Souza ${ }^{4}$
}

\section{RESUMO}

O mercado de derivativos é relativamente recente no agronegócio brasileiro e visa, entre outros, a minimizar riscos na comercialização. A comercialização dos produtos é uma das etapas mais importantes da atividade agropecuária. Diversos trabalhos têm enfocado a variação de preços dos produtos como uma das principais fontes de risco para o produtor rural. Por outro lado, tem sido questionado porque os produtores não utilizam ampla e significantemente os mecanismos dos mercados de derivativos, para se protegerem contra tais riscos. O objetivo deste trabalho foi entender a adequação desses mecanismos às atitudes dos produtores de soja, para reduzir riscos de preço do produto, tendo como foco produtores da região de Rio Verde, Goiás. O conhecimento dos produtores sobre derivativos não se mostrou dependente da escolaridade e da dimensão da área de plantio e sim dos anos de experiência na atividade. A escolha da modalidade de comercialização da safra, também, não apresentou dependência da escolaridade, da área de plantio, ou mesmo da experiência na atividade. Os meios utilizados pelos produtores, para se aproximarem das operadoras de derivativos, embora pouco frequentes, são diversificados, destacando-se a Cooperativa local como o meio mais procurado. Por outro lado, na percepção da maioria dos produtores, os derivativos não atendem às suas expectativas para minimizar risco de preço, mesmo entre aqueles que utilizam esses mecanismos de comercialização. Diante da falta de divulgação e da desconfiança apontadas pelos produtores, associadas a uma incipiente relação direta com as corretoras de derivativos, sugere-se uma mudança de estratégias e de atitudes das corretoras, no sentido de buscar aproximação e comprometimento junto aos produtores, para esclarecer e facilitar tomadas de decisão conscientes, em relação ao uso de derivativos.

Palavras-chave: Comercialização da soja, gestão de risco, derivativos.

\section{ABSTRACT}

\section{Agricultural derivatives as a mechanism for trading soybeans in Rio Verde, Goiás State, Brazil}

The derivatives market is relatively new in the Brazilian agribusiness and aims, among others, to minimize risks in trading. Trading agricultural products is one of the most important stages of farming. Several studies have focused on changes in prices of products as a major source of risk for the farmer. On the other hand, it has been questioned why farmers do not use more widely the mechanisms of the derivatives market, to protect themselves against such risks. The objective of this study was to investigate the adaptation of these mechanisms to the attitudes of soybean farmers in order to reduce price risks, focusing on farmers of the region of Rio Verde, Goiás. Knowledge of farmers on derivatives was not dependent on education and the size of the planting area, but on years of experience in the activity. Choosing

\footnotetext{
Recebido para publicação em 10/03/2010 e aprovado em 23/09/2011

' Artigo extraído da Dissertação de Mestrado do primeiro autor, Anhanguera - Uniderp.

2 Economista, Mestre. Departamento de Economia da Fesurv, Universidade de Rio Verde, Rua Trianon Qd. 9, Lt. 25, Residencial Maranata, 75911-055, Rio Verde, Goiás, Brasil. leo.economista@yahoo.com.br

${ }^{3}$ Engenheiro-Agrônomo, Ph.D. Universidade Anhanguera - Uniderp, Av. Alexandre Herculano, 1400, 79037-280, Campo Grande, Mato Grosso do Sul, Brasil.

${ }^{4}$ Licenciado em Matemática, Doutor. Universidade Anhanguera - Uniderp, Av. Alexandre Herculano, 1400, 79037-250, Campo Grande, Mato Grosso do Sul, Brasil.
} 
a mode for trading the crop was also not dependent on schooling, acreage, or even experience in the activity. The trading modes used by farmers to approach operators of derivatives, although infrequent, were diverse, being the local Cooperative the most sought after. On the other hand, under most farmers' view, derivatives do not meet their expectations to reduce price risks, even among those who use these trading mechanisms. Given the lack of information and suspicion pointed out by the farmers, in addition to an incipient direct relationship with derivatives brokers, it is suggested a change in the strategies and attitudes of brokers; they should seek approximation and commitment to the farmers, to clarify and facilitate a conscious decision-making on the use of derivatives.

Key words: Derivatives, risk management, trading of soybeans,.

\section{INTRODUÇÃO}

No Brasil, o mercado de derivativos é relativamente recente. Em 1986, foi fundada a Bolsa Mercantil e de Futuros e lançados os contratos de Índice de Bolsa de Valores de São Paulo. Em 1991, houve a junção da Bolsa Mercantil e de Futuros com a Bolsa de Mercadorias de São Paulo, surgindo a Bolsa de Mercadorias e de Futuros (BM\&F). Esses novos mecanismos têm sido indicados para reduzir riscos devidos à oscilação dos preços dos produtos agrícolas.

A gestão de risco na agricultura surge como uma necessidade, uma vez que está sujeita, principalmente, a dois tipos de riscos: o de produção e o de preço (Marques \& Aguiar, 2004; Abussamra, 2006). Os riscos de produção compreendem perdas por estiagens, geadas, enchentes, doenças, pragas e, até mesmo, por máquinas mal reguladas. Entretanto, tais riscos podem, circunstancialmente, ser amenizados por meio de bom manejo, de tecnologias adequadas e de seguro rural. Já os riscos de preços são mais difíceis de serem evitados, pois estão fora do controle do produtor e variam de acordo com o comportamento dos mercados interno e externo. Esses, muitas vezes, sofrem influência de vários fatores, como: boatos, previsões de clima, estimativas de safras, estoques e variação cambial, dentre outros.

O mercado de derivativos, dentre eles, mercado futuro, ainda é pouco conhecido entre os produtores e tem grande potencial a ser desenvolvido, apesar do volume expressivo de transações. Em síntese, os mercados futuros proporcionam a fixação do preço dos produtos, por meio da negociação de contratos que serão liquidados em data futura. Ao comprar ou vender esses contratos, nos pregões das Bolsas, os agentes envolvidos nas negociações previnem-se contra as oscilações de valores na comercialização agrícola.

Até há pouco tempo, o produtor, praticamente, só se preocupava com a comercialização da safra após a colheita. Isso era propiciado pela disponibilidade de crédito de custeio, antecipado e abundante. Durante muitos anos, os produtores brasileiros plantaram com a certeza de pre- ços garantidos pelo Governo. Os empréstimos e a aquisição do Governo Federal (EGF e AGF) eram as certezas de receitas e prováveis lucros ao final da safra.

Ao se limitarem os mecanismos governamentais, é incompreensível que os agentes que atuam no agronegócio não utilizem ampla e significantemente as ferramentas dos mercados derivativos. Nesse sentido, Batalha (1997), Marques \& Aguiar (2004) e Marques et al. (2006) ressaltaram que a falta de conhecimento condiciona o uso de derivativos.

Face aos fatos anteriormente citados e levando-se em consideração a influência econômica da soja dentro do agronegócio brasileiro e, mesmo mundial, escolheu-se esse produto como referência para essa pesquisa. Por sua representatividade, no contexto evolutivo das transformações e modernização do agronegócio brasileiro, associada à sua significativa importância socioeconômica na região centro-oeste, o município de Rio Verde, Goiás, foi selecionado para este estudo, tendo como foco de pesquisa os produtores de soja.

O objetivo do trabalho foi analisar o uso de derivativos de mercado agropecuário nas operações de comercialização de soja, e suas implicações, visando a entender a adequação desses mecanismos às atitudes dos produtores, para reduzir riscos devidos às variações de preços do produto.

\section{MATERIAL E MÉTODOS}

Considerando-se que o estudo visa a analisar e entender o uso de derivativos de mercado agropecuários, pelos produtores rurais, para comercialização de soja, a pesquisa se caracteriza como exploratória e descritiva. Como base para o desenvolvimento do trabalho, buscou-se, inicialmente, o entendimento dos conceitos e dos mecanismos operacionais que suportam as modalidades de derivativos, a partir de pesquisa bibliográfica. Para atender à essência da pesquisa, utilizou-se o método de entrevistas, por meio de questionário estruturado, aplicado a uma amostra de produtores rurais. 
Produtores de soja do município de Rio verde, Goiás, foram escolhidos como fonte de informação para o desenvolvimento da pesquisa. Com uma população estimada em 160.000 mil habitantes, o município tem-se destacado na produção de grãos, especificamente, a soja, atingindo uma produção estimada, em 2007, de 579.600 toneladas, cultivadas em 230.000 hectares (SEPIN, 2009). Essa produção representa $22,36 \%$ da produção total da região do sudoeste Goiano, 9,76\% da produção do estado e 1,0\% da produção de soja brasileira.

Segundo dados do SEPIN (2009), o município conta com 430 produtores de soja. Sobre essa população, utilizando a fórmula simplificada de Yamane (1967), citado por Francischini (2001) (1), e um erro amostral de 7\%, o tamanho da amostra estimada $(n)$ foi de 100 produtores. Entretanto, foram selecionados, de forma aleatória, 120 produtores, utilizando-se procedimentos computacionais disponíveis em Excel.

$$
n=\frac{N}{1+N(e)^{2}}
$$

em que:

$n=$ tamanho da amostra;

$N=$ tamanho da população; e

$e=$ erro amostral.

Após um pré-teste, a estrutura do questionário incorporou informações demográficas, recursos existentes, atividades desenvolvidas, além de aspectos relacionados com a comercialização, foco da pesquisa, totalizando 21 perguntas. Para facilitar o desenvolvimento da base de dados e posterior análise, o questionário foi formatado, utilizando-se o "software" Sphinx, Léxica 5.0. A formatação permitiu a transferência direta dos dados dos questionários para a base de dados do Sphinx, sem estágios intermediários. O questionário foi aplicado individualmente, durante o mês de março de 2009.

Sobre a base de dados foi aplicada análise univariada, seguida de análises bivariada e multivariada. A análise univariada foi aplicada para descrever e caracterizar a população. A análise bivariada teve como objetivo identificar possíveis interdependências entre pares de variáveis. Nesse sentido, as análises constituíram-se nos cruzamentos de informações quanto ao grau de conhecimento e às formas de negociação existentes, relacionando-as com variáveis demográficas (faixa etária, escolaridade e experiência) e área da propriedade. Cada análise foi acompanhada do teste de Qui-quadrado, para verificação da interdependência entre as variáveis, com nível de significância indicado pelo valor de p. Conforme Fonseca $\&$ Martins (1994), quando 0,01 $\leq p<0,05$, diz-se que existe uma dependência significativa entre as variáveis, quando
$0 \leq \mathrm{p}<0,01$, diz-se que essa dependência é muito significativa e, quando $\mathrm{p} \geq 0,05$, diz-se que a dependência não é significativa.

Na análise multivariada, optou-se pela utilização da análise de correspondência múltipla (ACM), para verificar associações ou similaridades entre variáveis. Por meio de representação gráfica, as posições das categorias de cada variável, no plano multidimensional, no caso representado pelos eixos vertical e horizontal, podem ser interpretadas como associações. Para interpretá-las, é preciso levar em conta que, quanto menor a distância euclidiana entre duas categorias, mais associadas entre si elas estão. Além disso, o tamanho da representação gráfica do indicador (variável) representa a freqüência. Ou seja, quanto maior o tamanho dessa representação, maior é a freqüência.

Para essa análise, selecionaram-se grupos de variáveis formados por faixa etária, escolaridade, área da propriedade, experiência, importância do conhecimento dos derivativos na comercialização da soja e modalidades de comercialização utilizadas.

\section{RESULTADOS E DISCUSSÃO}

\section{Descrição e caracterização da população: análise univariada}

Identificou-se que $94 \%$ dos produtores são homens, com predominância de idade abaixo de 50 anos (68\%), faixa etária que pode ser favorável à capacidade de inovação no agronegócio. Em geral, os produtores do município têm uma vasta experiência, pois $71,2 \%$ estão há mais de seis anos na atividade, destacando-se um grupo significativo de 47,5\% com mais de dez anos. Perfis semelhantes foram observados por Tres (2009), em relação aos produtores de Lucas do Rio Verde, Sorriso e Sinop, no Mato Grosso, região produtora de soja, mostrando que 73,5\% dos produtores estão abaixo de 50 anos e a maioria (95\%) está há mais de seis anos na atividade.

Em relação à escolaridade, verificou-se que os sojicultores da região de Rio Verde apresentam razoável formação, sendo que 34,7\% possuem, no mínimo, o ensino médio completo e $34 \%$ tiveram acesso a curso superior, com $22 \%$ de conclusão. Nesse sentido, foi constatado que, entre os que completaram curso superior, $20 \%$ são formados nas áreas de Ciências Agrárias, o que é um fator muito relevante para o agronegócio da região. Isso pode ser um indicativo de que os novos produtores rurais estão investindo em suas qualificações, com a expectativa de maiores possibilidades de sucesso nos seus negócios. O estudo de Tres (2009), também revelou que, aproximadamente, $35 \%$ dos produtores possuem ensino médio completo; porém, apresenta um percentual bastante inferior em relação ao ensino superior completo (11,3\%). De 
acordo com a pesquisa da Fundação Getulio Vargas (1999), a educação é essencial para promover e elevar a renda dos estabelecimentos e permanecer na atividade. Assim, escolaridade é quase uma imposição aos agricultores para um novo padrão de produção no campo.

É reconhecido que, isoladamente, o produtor entra em desvantagem, em relação aos compradores e vendedores, na hora de negociar a venda de seus produtos e a aquisição de insumos. Na tentativa de superar essa desvantagem, os produtores unem-se em associações ou cooperativas. Em Rio Verde, não é diferente: de acordo com a pesquisa, $51,7 \%$ dos produtores unem-se sob alguma forma de associativismo. Dos que são associados, a maioria, não de forma excludente, prefere a Cooperativa Mista dos Produtores Rurais do Sudoeste Goiano Ltda - COMIGO, como alternativa de associativismo. Essa cooperativa destaca-se no desenvolvimento da sojicultura na região, sendo, inclusive, o marco inicial para o processamento industrial da soja.

Informação e conhecimento são cruciais no processo de tomadas de decisão. Em geral, informações são procuradas e, ou, oferecidas em diversas fontes e formas, visando a auxiliar os produtores nas suas decisões. Entre as fontes de informações pesquisadas, a Tabela 1 mostra que, na média, "Programas Rurais na TV" é a que mais se destaca, posicionando-se na faixa entre importante e muito importante.

Entretanto, os resultados também indicam uma significante participação de outras fontes que, em ordem decrescente de importante a moderada importância, aparecem "Assessoria Técnica Privada", "Páginas na Internet", "Revista Agropecuária", "Embrapa", "Jornal" e "Vizinhos Fazendeiros". Na faixa de pouca a moderada importância, situam-se a "Associação de Produtores" e os "Bancos". Tais resultados são evidências claras de que os produtores da região utilizam uma diversidade de fontes de informação, assim como as respectivas impor-

Tabela 1. Ordem de importância de fontes de informação nas decisões dos sojicultores, no município de Rio Verde, Goiás

\begin{tabular}{lcc}
\hline Descrição & Média* $^{*}$ & Desvio Padrão \\
\hline Programas Rurais na TV & 4,21 & 1,37 \\
Assessoria Técnica privada & 3,80 & 1,10 \\
Páginas na Internet & 3,66 & 1,53 \\
Revista Agropecuária & 3,62 & 1,49 \\
Embrapa & 3,55 & 1,34 \\
Jornal & 3,14 & 1,43 \\
Vizinhos Fazendeiros & 3,12 & 1,23 \\
Associação de Produtores & 2,96 & 1,42 \\
Bancos & 2,75 & 1,43 \\
Outras & 1,46 & 1,27 \\
\hline
\end{tabular}

*1 = nenhuma importância; 2 = pouca importância; $3=$ moderada importância; 4 = importante; 5 = muito importante. tâncias relativas, para tomadas de decisões. Em geral, os produtores rurais, mesmo desenvolvendo atividades distintas, apresentam grande semelhança quanto à importância dada às fontes de informação disponíveis. Cezar (2000) identificou que pecuaristas do Mato Grosso do Sul também consideraram "Programas Rurais na TV" e "Revistas Agropecuárias” entre as mais importantes.

A Figura 1 indica que somente uma pequena parcela $(15,3 \%)$ dos produtores detém muito conhecimento sobre derivativos agropecuários, enquanto $72 \%$ dividem-se entre possuir conhecimento de moderado $(34,7 \%)$ a conhecimento suficiente $(37,3 \%)$. Independentemente da proporção da safra comercializada, foi possível verificar que $30,8 \%$ dos produtores que relataram possuir muito conhecimento e $61,5 \%$ com suficiente conhecimento utilizaram derivativos (mercado futuro), enquanto aqueles com moderado, pouco e nenhum conhecimento totaliza$\operatorname{ram} 7,7 ; 0,0$ e $0,0 \%$, respectivamente, no uso dessa modalidade de comercialização.

Embora, reconhecendo que a pesquisa não caracterizou cada grau de conhecimento e baseou-se na percepção do entrevistado, estes resultados remetem ao questionamento "por qual motivo" a totalidade dos produtores, que relataram possuir muito e suficiente conhecimento, não comercializam por meio de derivativos. Por outro lado, ficou evidente que a falta de conhecimento pode explicar a restrição na utilização dessas modalidades de comercialização, uma vez que os produtores que relataram pouco e nenhum conhecimento não utilizaram derivativos. Em estudo no Paraná, Marques \& Aguiar (2004) também identificaram que entre os produtores de soja que nunca utilizaram mercados futuros, $57 \%$ não conheciam essa modalidade de comercialização e entre os produtores que disseram conhecê-los, 27\% justificaram sua não utilização por não conhecerem o suficiente. Os autores ainda apontam que apenas $13 \%$ dos produtores que disseram conhecer mercados futuros já operavam com essa modalidade.

Verificou-se que os produtores rurais desdobram sua produção na hora de comercializar, diversificando-se em várias formas de comercialização (Tabela 2). Embora as modalidades de comercialização utilizadas não sejam excludentes e, independentemente das proporções da produção distribuídas entre elas, pôde-se observar que, em ordem decrescente, 78,7\% dos produtores negociam em Venda à Vista, 50\% em Cooperativas, 48,30\% em Base de Troca, 36,40\% em Empresas Esmagadoras, 23,70\% em Mercado Futuro, 19,50\% em CPR, 17,80\% em Empresas Exportadoras e, com menor frequência, em Opção e em Swap, atingindo somente 9,30 e 2,50\% dos produtores, respectivamente. Percebe-se, portanto, que os produtores procuram diversificar as suas formas de comercialização. Entretanto, ficou evidenciado que tanto a preferência como a 


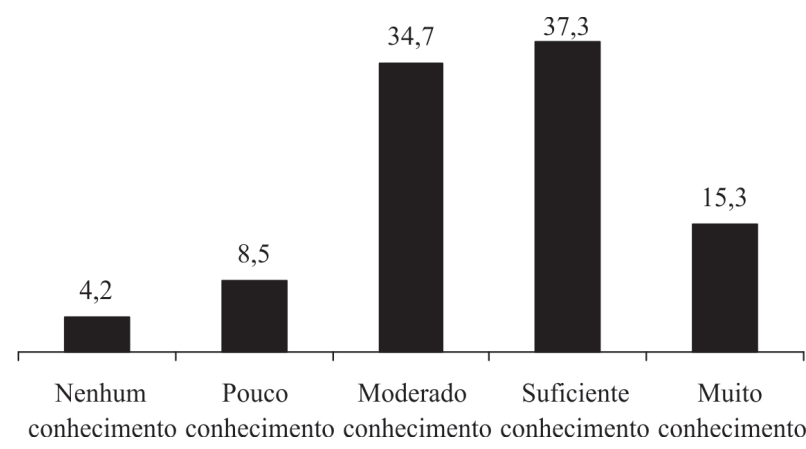

Figura 1. Conhecimento sobre os derivativos agropecuários dos sojicultores de Rio Verde, Goiás.

maior parte da produção estão direcionadas para as modalidades não relacionadas com derivativos. A venda por meio da Base de Troca tem sido um mecanismo utilizado pelos produtores para financiar aquisição de insumos, a serem quitados com parte da produção de grãos.

Embora com baixas frequências, os meios utilizados pelos produtores para se aproximarem das operadoras de derivativos são diversificados. Entretanto, a "Cooperativa" destaca-se como o principal meio, seguido pela influência de "Amigos". Esses resultados podem ser considerados como indicativos de que os produtores utilizam "meios" que lhe proporcionam maior grau de confiança e proximidade de relações. Adicionalmente, "segurança" e "conhecimento sobre o assunto" destacaram-se como fatores indutores da utilização de derivativos.

Na percepção dos produtores, embora com alta variação, os derivativos não atendem à expectativa de redução de risco, sendo a média para o mercado futuro situada entre pouco e moderado atendimento.

Verificou-se que o fator desconfiança ainda continua tendo influência, impedindo que muitos empresários utilizem derivativos para reduzirem riscos. $\mathrm{O}$ mesmo ocorre em relação à divulgação. Complementando, pode-se dizer que a falta de conhecimento, ainda é o grande problema, pois alguns produtores têm algumas informações, mas são poucas as pessoas que detêm conhecimento específico dos processos e como funcionam os derivativos.

Em geral, a burocracia que permeia as questões legais e contratuais ligadas ao agronegócio, tem sido duramente criticada pelos produtores. Seja por causa do efeito de ordem psicológica, ou não, ficou evidenciada a influência da "burocracia", como limitante ao uso de derivativos.

Esses resultados indicam que a percepção e o comportamento dos produtores rurais confrontam com os fundamentos teóricos e operacionais que suportam os mercados derivativos, como instrumentos de comercialização para minimizar risco de preço. A literatura é convergente na indicação dos mercados futuros para reduzir riscos de preços (Teixeira, 1992; Souza \& Marques, 1994; Marques \& Mello, 1999; Hull, 1998; Marques, 2000; Carter, 2003; Marques et al., 2006; Pereira, 2008; Adami et al., 2008; Moraes et al., 2009; Concórdia, 2011; TerraFuturos, 2011). A abrangência e a extensão dos aspectos operacionais e financeiros dos mercados de derivativos transcendem à discussão neste artigo. Entretanto, cabe argumentar, em relação à posição dos hedgers (vendedores e compradores) que, segundo Marques et al. (2006), caracterizam a participação dos produtores rurais no mercado futuro que, no caso, os vendedores detêm o produto físico e entram no mercado, buscando segurança contra uma baixa de preços em uma data predeterminada no futuro. A negociação no mercado futuro implica o compromisso de receber e de entregar o objeto do contrato, em um mês préestabelecido, por um preço combinado na assinatura do contrato, sujeitos à compensação de pequenos ajustes diários, para mais ou para menos. Pereira (2008) ressaltou que os hedgers utilizam estes mercados como ferramenta de gerenciamento de risco de preço, ou seja, não visam a obter lucro nas operações realizadas. Segundo esse autor, o objetivo dos hedgers é garantir o preço de venda do ativo com o qual estão envolvidos em sua atividade. Neste caso, qualquer que seja o andamento dos preços dos ativos no mercado à vista, o investidor (hedger) tem a

Tabela 2. Distribuição das modalidades de comercialização dos sojicultores de Rio Verde, Goiás

\begin{tabular}{|c|c|c|c|c|}
\hline \multirow{3}{*}{ Forma de Comercialização } & \multicolumn{4}{|c|}{ \% da produção } \\
\hline & $0 \%$ & 1 a $30 \%$ & 31 a $60 \%$ & 61 a $100 \%$ \\
\hline & \multicolumn{4}{|c|}{ Frequência (\% de produtores) } \\
\hline Venda à vista & 22,0 & 30,3 & 19,4 & 28,3 \\
\hline Cooperativas & 50,0 & 19,5 & 14,5 & 16,0 \\
\hline Base de Troca & 51,7 & 39,2 & 5,0 & 4,1 \\
\hline Empresas Esmagadoras & 63,6 & 28,1 & 5,0 & 3,3 \\
\hline Mercado Futuro & 76,3 & 20,9 & 2,8 & 0,0 \\
\hline CPR (Cédula do Prod. Rural) & 80,5 & 17,6 & 1,1 & 0,8 \\
\hline Empresas Exportadoras & 82,2 & 16,0 & 1,8 & 0,0 \\
\hline Opção & 90,7 & 9,3 & 0,0 & 0,0 \\
\hline Swap & 97,5 & 2,5 & 0,0 & 0,0 \\
\hline
\end{tabular}


garantia de determinado preço para esse mesmo ativo em certa data futura, argumentou Pereira (2008). Diante dessas argumentações e da fundamentação disponível, torna-se surpreendente a posição dos produtores rurais em relação aos mercados futuros, indicando a necessidade de pesquisa para esclarecer essa questão, o que não foi possível com os resultados deste trabalho.

Quanto ao custo de produção, a maioria dos produtores $(83 \%)$ informou que sabe quanto custa produzir um saco de soja. Isto é um indicativo de que os produtores rurais estão evoluindo e preocupados com a rentabilidade de seu negócio. Verificou-se que a gestão financeira da atividade é exercida pela maioria dos produtores (73,7\%), seguida por funcionário, empresas especializadas e, em menor proporção, pelas esposas. Nesse sentido, identificou-se que 36,6\% dos responsáveis pela gestão financeira das propriedades possuem curso superior, seguida de $28,2 \%$ com o ensino médio completo.

\section{Relações entre variáveis: análise bivariada Idade $X$ escolaridade}

A idade e a escolaridade podem ser fatores decisivos no empreendimento, pois essas duas variáveis podem influenciar nas decisões do produtor. Assim, foi feito o cruzamento entre as variáveis idade e escolaridade, indicando interdependência muito significativa $\left(\chi^{2}=31,77, \mathrm{gl}=8\right.$, 1 - $p=99,99 \%$ ) na relação entre estas duas variáveis (Tabela 3). Entretanto, como existem 5 (33,3\%) células que têm frequências teóricas inferiores a 5, as regras do Qui-quadrado não são realmente aplicáveis. Assim, a confirmação da interdependência foi feita por meio do Teste Exato de Fisher $(p=0,000)$, usando a Simulação de Monte Carlo.

Da análise da Tabela 3, deduz-se que existe uma relação inversa entre idade e nível de escolaridade, isto é, quanto mais idoso é o produtor, menor é a sua escolaridade. Outras leituras podem ser feitas da Tabela 3, destacando-se que $90 \%$ dos produtores entre 18 e 24 anos enquadram-se em nível de ensino superior, $37 \%$ dos produtores com idade acima de 50 anos só possuem o nível fundamental e somente $13,5 \%$ desses possuem cursos superiores.

\section{Experiência X grau de conhecimento sobre derivativos}

Identificou-se dependência muito significativa $\left(\chi^{2}=45,36, \mathrm{gl}=12,1-\mathrm{p}=>99,99 \%\right.$; Teste de Fisher $\mathrm{p}=$ $0,001)$ na relação entre experiência e grau de conhecimento sobre derivativos. A Tabela 4 mostra que, à medida que aumentam os anos de experiência na atividade, aumenta o grau de conhecimento sobre derivativos. Este resultado, supostamente, era esperado; porém, dada a importância desses mecanismos de comercialização, é necessário divulgá-los entre os menos experientes.

\section{Idade X grau de conhecimento sobre derivativos}

Verificou-se não haver interdependência significativa $\left(\chi^{2}=22,41, \mathrm{gl}=16,1-\mathrm{p}=86,96 \%\right.$; Teste de Fisher $\left.\mathrm{p}=0,12\right)$ na relação entre idade e conhecimento sobre derivativos. Percebe-se na Tabela 5 que todas as faixas de idade acreditam possuir de moderado a suficiente conhecimento a respeito de derivativos agropecuários. Embora a maioria dos produtores da faixa etária de 18 a 24 anos possua curso superior, $30 \%$ afirmaram deter pouco conhecimento sobre derivativos, $50 \%$ moderado conhecimento e somente $20 \%$ suficiente conhecimento. Neste caso, por serem jovens, a pouca experiência pode ter influência, uma vez que ficou demonstrado haver dependência muito significativa entre experiência e grau de conhecimento sobre derivativos. Destaca-se, também, que 70,6\% da faixa etária entre 25 e 29 anos acreditam possuir de suficiente a muito conhecimento sobre os derivativos.

\section{Associações entre variáveis: análise multivariada}

$\mathrm{Na}$ análise multivariada, é possível verificar graficamente as associações formadas por duas, três ou até mais variáveis. Para isso, utilizou-se a técnica da Análise de Correspondência Múltipla (ACM) para verificar as associações ou similaridades entre variáveis.

A Figura 2 apresenta as associações encontradas entre faixa etária, escolaridade, grau de conhecimento sobre derivativos agropecuários e modalidades de comercializa-

Tabela 3. Cruzamento de idade com a escolaridade dos sojicultores de Rio Verde, Goiás

\begin{tabular}{lcccc}
\hline \multirow{2}{*}{ Idade } & \multicolumn{3}{c}{ Nível de escolaridade (\%) } & \multirow{2}{*}{ Total } \\
\cline { 2 - 3 } & Fundamental & Médio & Superior & 100 \\
\hline De 18 a 24 anos & 10,0 & 00,0 & 90,0 & 100 \\
De 25 a 29 anos & 11,8 & 29,4 & 58,8 & 100 \\
De 30 a 39 anos & 10,0 & 60,0 & 30,0 & 100 \\
De 40 a 49 anos & 17,6 & 52,9 & 29,4 & 100 \\
acima de 50 anos & 37,8 & 48,6 & 13,5 & 100 \\
\hline Total & 21,2 & 44,9 & 33,9 & \\
\hline
\end{tabular}

Obs. A dependência é muito significativa $x^{2}=31,77, \mathrm{gl}=8,1-\mathrm{p}=99,99 \%$.

Rev. Ceres, Viçosa, v. 58, n.5, p. 567-575, set/out, 2011 
Tabela 4. Cruzamento do tempo de experiência no ramo com o grau de conhecimento sobre derivativos dos sojicultores de Rio Verde, Goiás

\begin{tabular}{|c|c|c|c|c|c|}
\hline \multirow{3}{*}{ Grau de conhecimento } & \multicolumn{4}{|c|}{ Experiência (anos) } & \multirow{3}{*}{ Total } \\
\hline & Até 3 & $>3$ a 6 & $>6$ a 10 & $>10$ & \\
\hline & \multicolumn{4}{|c|}{$\%$} & \\
\hline Nenhum conhecimento & 07,1 & 10,0 & 00,0 & 01,8 & 03,4 \\
\hline Pouco conhecimento & 50,0 & 00,0 & 00,0 & 05,3 & 08,5 \\
\hline Moderado conhecimento & 21,4 & 45,0 & 44,4 & 29,8 & 34,7 \\
\hline Suficiente conhecimento & 14,3 & 25,0 & 40,7 & 47,4 & 38,1 \\
\hline Muito conhecimento & 07,1 & 20,0 & 14,8 & 15,8 & 15,3 \\
\hline Total & 100 & 100 & 100 & 100 & 100 \\
\hline
\end{tabular}

Obs. A dependência é muito significativa. $x^{2}=45,36$, gl = 12, 1-p = > 99,99\%. No Teste Exato de Fisher - Simulação de Monte Carlo obtevese $\mathrm{p}=0,001$ mostrando que, realmente, a dependência é muito significativa.

Tabela 5. Cruzamento entre idade com o grau de conhecimento de derivativos dos sojicultores de Rio Verde, Goiás

\begin{tabular}{|c|c|c|c|c|c|c|}
\hline \multirow{3}{*}{ Grau de conhecimento } & \multicolumn{5}{|c|}{ Idade (anos) } & \multirow{3}{*}{ Total } \\
\hline & 18 a 24 & 25 a 29 & 30 a 39 & 40 a 49 & $>\mathbf{5 0}$ & \\
\hline & \multicolumn{5}{|c|}{$\%$} & \\
\hline Nenhum conhecimento & 00,0 & 05,9 & 05,0 & 05,9 & 00,0 & 03,4 \\
\hline Pouco conhecimento & 30,0 & 11,8 & 05,0 & 05,9 & 05,4 & 08,5 \\
\hline Moderado conhecimento & 50,0 & 11,8 & 25,0 & 41,2 & 40,5 & 34,7 \\
\hline Suficiente conhecimento & 20,0 & 35,3 & 45,0 & 35,3 & 43,2 & 38,1 \\
\hline Muito conhecimento & 00,0 & 35,3 & 20,0 & 11,8 & 10,8 & 15,3 \\
\hline Total & 100 & 100 & 100 & 100 & 100 & 100 \\
\hline
\end{tabular}

Obs.: A dependência é pouco significativa. $x^{2}=22,41, \mathrm{gl}=16,1-\mathrm{p}=86,96 \%$. Atenção, 15 (60,0\%) células têm uma frequência teórica inferior a 5, as regras do Qui-quadrado não são realmente aplicáveis. No Teste Exato de Fisher - Simulação de Monte Carlo obteve-se p = 0,12 mostrando que, realmente, a dependência não é significativa.

ção utilizadas. Embora a variância explicada seja baixa, observa-se que alguns subconjuntos como, por exemplo, os produtores na faixa etária de 30 a 39 anos e que possuem o ensino médio, acreditam possuir suficiente conhecimento sobre derivativos, mas preferem vender as suas safras às cooperativas, em primeiro lugar, empresas esmagadoras, em segundo, e venda à vista, em terceiro. Também comercializam, em pouca quantidade, no mercado futuro e na exportação. Já produtores acima de 40 anos, com ensino fundamental, apresentam pouco ou moderado conhecimento sobre derivativos e comercializam suas safras na base de troca e à vista. Produtores na faixa etária de 18 a 24 anos, com curso superior, admitem possuir pouco conhecimento dos derivativos e preferem comercializar as suas safras no mercado à vista, CPR e outras modalidades. Finalmente, produtores entre 24 e 29 anos, com ensino superior, já consideram possuir muito conhecimento sobre derivativos e comercializam as suas safras à vista ou entregam diretamente às empresas esmagadoras. As variâncias explicadas pelos eixos dos x e dos y são baixas, respectivamente, 6,61 e $6,57 \%$. A soma das percentagens de variância explicada pelos eixos da representação indica a parte de informação restituída pela ACM. Quanto mais próxima de $100 \%$, melhor é a análise.
Na Figura 3, buscou-se verificar as associações ou similaridades entre escolaridade, tamanho da propriedade, e grau de conhecimento sobre derivativos agropecuários e modalidades de comercialização utilizadas. Nessa figura, também, com baixa variância explicada, percebe-se alguns agrupamentos. O primeiro, de produtores que possuem de 01 a 400 hectares de terra, que detêm ensino médio, acreditam ter de moderado a suficiente conhecimento dos derivativos e que vendem as suas safras, preferencialmente, à vista; em segundo, preferem as cooperativas e, em terceiro lugar, utilizam a base de troca na comercialização. Nesse subconjunto, também estão incluídos produtores que possuem mais de 1.600 hectares de terra. Um pequeno subconjunto de produtores são os que possuem entre 401 e 800 hectares, com ensino fundamental, caracterizando-se por nenhum ou pouco conhecimento dos derivativos e que preferem, também, comercializar suas safras à vista ou à base de troca. O bloco dos produtores que possuem de 801 a 1.600 hectares têm ensino superior, possuem muito conhecimento dos derivativos e também comercializam à vista, na base de troca, mas utilizam ainda empresas esmagadoras e mercado futuro como opções de comercialização. 


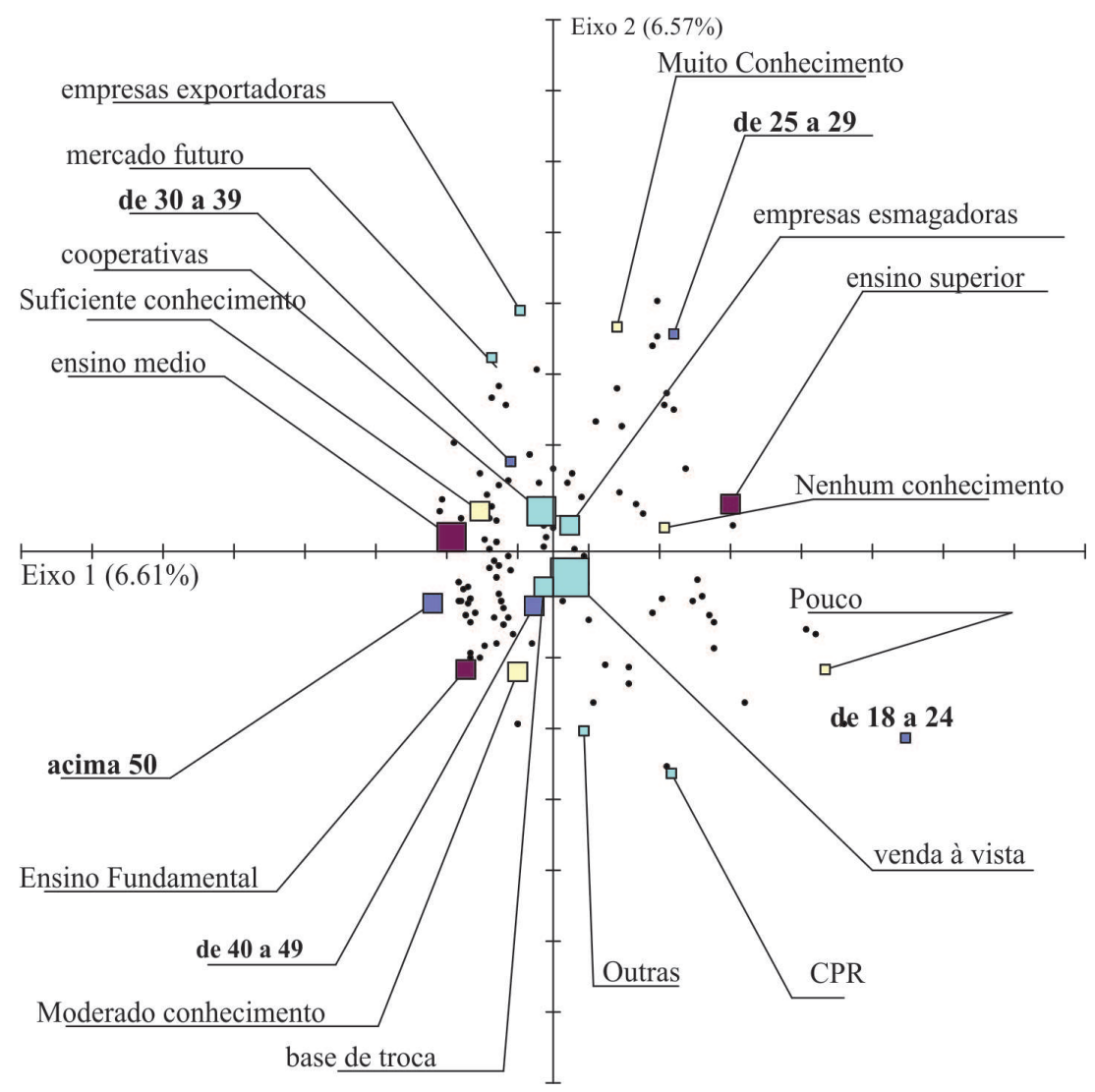

Figura 2. Gráfico fatorial de associações ou similaridades entre faixas etárias, escolaridade, grau de conhecimento sobre derivativos agropecuários e modalidades de comercialização utilizadas pelos sojicultores de Rio Verde, Goiás.

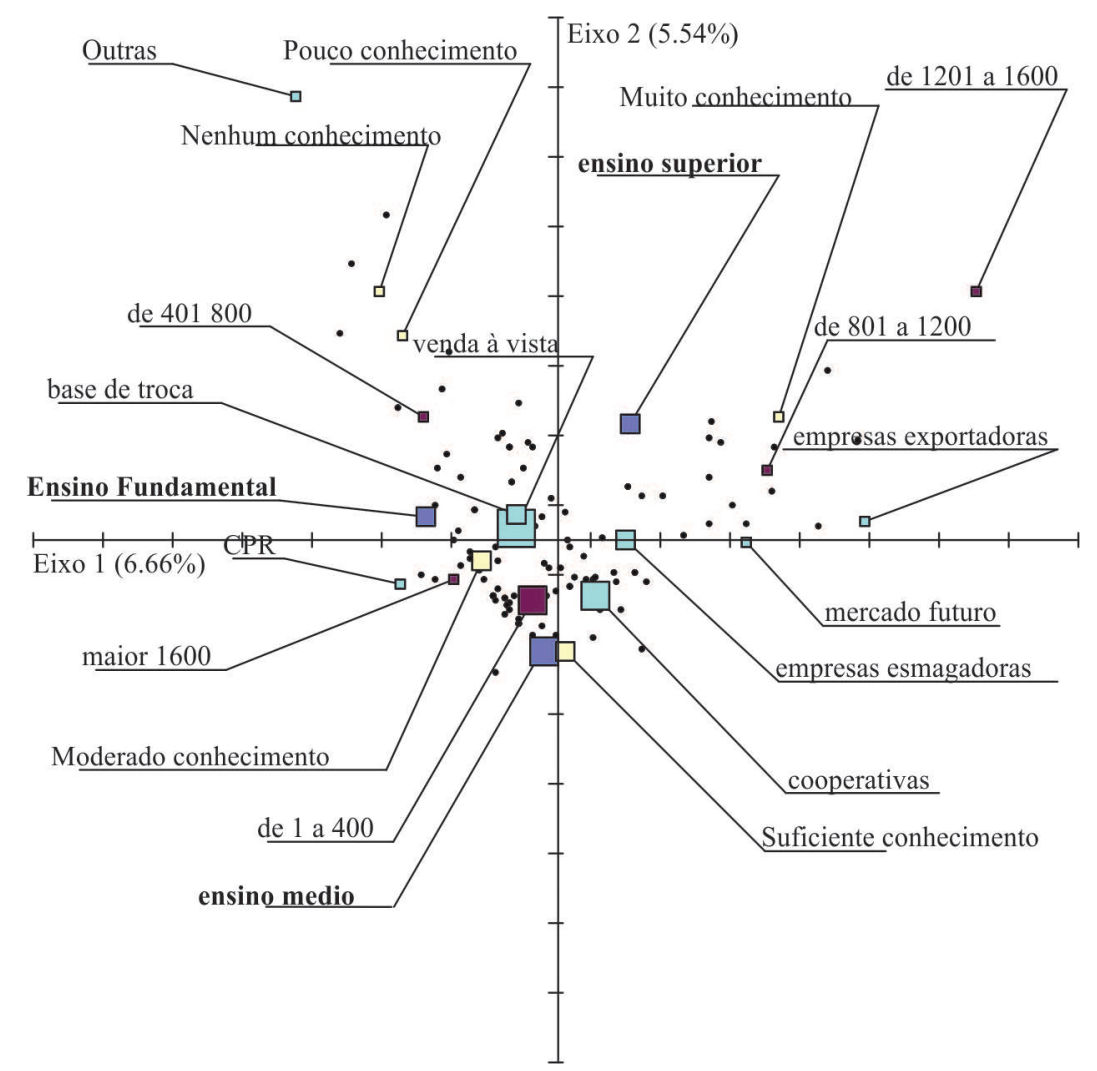

Figura 3. Gráfico fatorial de associações ou similaridades entre escolaridade, tamanho da propriedade, grau de conhecimento sobre derivativos agropecuários e modalidades de comercialização utilizadas pelos sojicultores de Rio Verde, Goiás.

Rev. Ceres, Viçosa, v. 58, n.5, p. 567-575, set/out, 2011 


\section{CONCLUSÕES}

Comercialização por meio de derivativos agropecuários não é uma prática usual entre os produtores de soja, embora tais mecanismos sejam de conhecimento da maioria. De fato, a comercialização é diversificada, porém predomina a venda à vista, absorvendo o maior volume da produção.

O conhecimento dos produtores sobre derivativos não é dependente da escolaridade e da dimensão da área de plantio e sim dos anos de experiência na atividade. A escolha da modalidade de comercialização da safra, também, não depende da escolaridade, da área de plantio, ou mesmo da experiência na atividade.

Os meios utilizados pelos produtores, para se aproximarem das operadoras de derivativos, embora pouco frequentes, são diversificados, destacando-se a Cooperativa local como o meio mais procurado. Por outro lado, na percepção da maioria dos produtores, os derivativos não atendem às suas expectativas para minimizar risco de preço, mesmo entre aqueles que utilizam esses mecanismos de comercialização.

Diante da falta de divulgação e da desconfiança apontadas pelos produtores, associadas a uma incipiente relação direta com as corretoras de derivativos, sugere-se uma mudança de estratégias e de atitudes das corretoras, no sentido de buscar aproximação e comprometimento junto aos produtores, para esclarecer e facilitar tomadas de decisão conscientes, em relação ao uso de derivativos.

O caráter exploratório do trabalho não permitiu explicar e entender outros aspectos e relacionamentos que limitam o uso efetivo dos derivativos, porém, aponta a necessidade de pesquisas específicas para ajudar a explicar os fatores causais das limitações no uso dessas modalidades de comercialização entre os produtores rurais. Entre outras, é necessário esclarecer as causas de não satisfação plena daqueles produtores que usam derivativos.

O comportamento de aversão, atração ou neutralidade em relação a risco é uma característica pessoal. Por isso, parece ser recomendáveis pesquisas que possam relacionar o uso de derivativos com o comportamento do produtor em relação a risco, ou seja, com os derivativos como instrumento para minimizar risco de preço.

Finalmente, ficou comprovado que o uso de derivativos ainda não ocupa lugar de destaque na comercialização da soja na região de Rio Verde, GO.

\section{REFERÊNCIAS BIBLIOGRÁFICAS}

Abussamra LF (2006) Gestão de riscos no agronegócio. Revista AgroAnalysis, 26.

Adami AC de O, Barros GS de C \& Bacchi MRP (2008) Contratos de opção: análise do potencial de sustentação de preços para o mercado de arroz. Revista de Economia e Sociologia Rural, 46:229-247.
Batalha MO (1997) Sistemas agroindustriais; definições e correntes metodológicas. In: Batalha MO (Coord.) Gestão agroindustrial. São Paulo, Atlas. p.23-48.

Carter CA (2003) Futures and options markets: an introduction. New Jersey, Upper Saddle River. 323p.

Cezar IM (2000) Conhecendo melhor os pecuaristas e suas relações com a Embrapa Gado de Corte. Campo Grande, Embrapa Gado de Corte. 49p. (Embrapa Gado de Corte. Boletim de Pesquisa, 09).

Concórdia (2011) Derivativos agropecuários - Mercado futuro. Disponível em: <http://www.concordia.com.br/downloads/investimentos/bmf/guia_derivativos_agropecuarios.pdf $>$. Acessado em: 23 de agosto de 2011.

Fundação Getúlio Vargas (1999) Perfil do agricultor brasileiro. Brasília, CNA Confederação Nacional da Agricultura. 48p.

Fonseca JS \& Martins GA (1994) Curso de estatística. 5a ed. São Paulo, Atlas.

Francischini R (2001) Uso de tecnologia da informação por produtores de café associados à Cooperativa Regional de Cafeicultores em Guaxupé - Cooxupé. Dissertação de Mestrado. Universidade Federal de Viçosa, Viçosa, 136p.

Hull J (1998) Opções, futuros e outros derivados. $3^{a}$ ed. São Paulo, BM\&F, Cultura Editores Associados. 609p.

Marques PV \& Mello PC de (1999) Mercados futuros de commodities agropecuárias: exemplos de aplicações para mercados brasileiros. São Paulo, Bolsa de Mercadorias \& Futuros. 208 p.

Marques PV (2000) Mercados futuros e de opções agropecuários. In: Zylbersztajn D \& Neves MF (Org.) Economia \& gestão dos negócios agroalimentares. São Paulo, Pioneira. p.211-234.

Marques PV, Mello PC de \& Martines JGF (2006) Mercados futuros e de opções agropecuárias. Disponível em: <http:// economia.esalq.usp.br/did/did-129.pdf >. Acessado em: 18 de agosto de 2011.

Marques RHS \& Aguiar DRD (2004) Determinantes do uso de mercados futuros pelos produtores de soja no município de Cascavel, PR. Revista de Economia e Agronegócio, 2:209-234.

Moraes AS, Lima RC \& Melo AS (2009) Análise da eficiência do mercado futuro brasileiro de boi gordo usando co-integração. Revista de Economia e Sociologia Rural, 47:601-614.

Pereira R (2008) Derivativos: um mercado fascinante, mas perigoso! Disponível em: <http://dinheirama.com/blog/2008/04/04/ derivativos-um-mercado-fascinante-mas-perigoso/>. Acessado em: 21 de agosto de 2011.

SEPIN (2009) Superintendência de Estatística, Pesquisa e Informação. Estatísticas municipais. Disponível em: <http:// www.seplan.go.gov.br/sepin/>. Acessado em: 01 de outubro de 2011.

Souza WA \& Marques PV (1994) O mercado futuro como instrumento de comercialização para o empresário rural. In: $18^{\circ}$ Encontro Anual da ANPAD, Curitiba. Anais, Anpad. p.53-76.

Teixeira MA (1992) Mercados futuros: fundamentos e característica operacionais. São Paulo, BM\&F. 19p.

TerraFuturos (2011) Mercados derivativos. Disponível em: <http:/ /www.terrafuturos.com.br/mercados_derivativos.php.> Acessado em 21 de agosto de 2011.

Tres CD de (2009) Adoção de instrumentos de administração e de tecnologia de informação na gestão da produção agropecuária no Estado de Mato Grosso. Dissertação de Mestrado. Universidade Anhanguera-Uniderp, Campo Grande, 69p. 